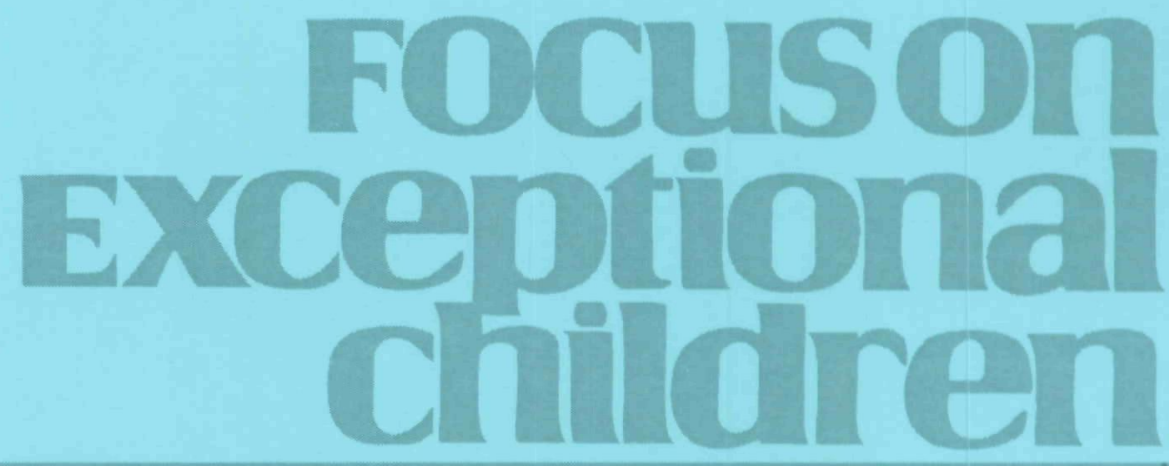

\title{
Using Technology to Support Progress Monitoring and Data-Based Intervention Decision Making in Early Childhood: Is There an App for That?
}

\author{
Jay Buzhardt, Dale Walker, Charles R. Greenwood, and Linda Heitzman-Powell
}

Like most of education, the field of Early Childhood Special Education (ECSE) is striving to find ways to implement evidence-based early intervention practices given limited resources, rising costs, increasing accountability requirements, and growing demand for services. In the face of continuing fiscal concerns (McNichol, Oliff, \& Johnson, 2011; Steinhauer, 2011), there is growing expectation that early childhood programs collect and report child-level results as a basis for individualizing intervention services and reporting their programwide impact and improvement processes (Snow \& Van Hemel, 2008; U.S. Department of Education, 2009). Evidence of this is the current Race to the Top-Early Learning Challenge competition, which encourages applicants to explore strategies to improve the implementation of data systems that inform individualized early intervention decisions (U.S. Department of Education, 2011). However, similar to the challenges faced by $\mathrm{K}-12$ education, early childhood programs also face significant barriers to implementing child-level, data-intensive approaches on a large scale because of costs in terms of time and training and a lack of supporting infrastructure, such as usable data systems, software, and appropriate progress-monitoring measures (Greenwood et al., 2011). These barriers must be addressed in order to scale up the use of progress monitoring and data-based decision-making practices within early childhood.

In this paper, we explore the potential for technology, specifically computer and web-based systems, to decrease the barriers to implementing data-based decision-making approaches in early childhood programs. We consider technology's role in supporting frequent progress monitoring and data-based intervention decision making by service providers often with limited training in these practices, as well as the empirical evidence to support this use of technology. We center this discussion on five primary questions:

1. What is progress monitoring and data-based decision making, and what challenges to implementing these practices can technology help address?

2. To what degree is computer-based technology ready for use in the field by early childhood practitioners?

Dr. Buzhardt is an associate research professor at Juniper Gardens Children's Project at the University of Kansas. Dr. Walker is an associate research professor at Juniper Gardens Children's Project at the University of Kansas. Dr. Greenwood is a senior scientist at Juniper Gardens Children's Project and professor in the Department of Applied Behavioral Sciences at the University of Kansas. Dr. Heitzman-Powell is an assistant research professor at Juniper Gardens Children's Project and director of community research and training at the Center for Child Health and Development at the University of Kansas Medical Center. 
3. As an example of a technology-supported data-based decision-making system for early childhood, how are Infant and Toddler IGDIs used for intervention decision making, and what is the evidence to support this use of technology?

4. What challenges have been identified in the use of technology to support progress monitoring and decision making in $\mathrm{K}-12$ education and medicine?

5. How can mobile devices support progress monitoring and intervention decision making?

\section{WHAT IS PROGRESS MONITORING AND DATA- BASED DECISION MAKING, AND WHAT CHAL- LENGES TO IMPLEMENTING THESE PRACTICES CAN TECHNOLOGY HELP ADDRESS?}

As described by Fuchs, Mock, Morgan, and Young (2003), data-based decision-making or problem-solving approaches within special education are grounded in the principle that "no student characteristic (e.g., disability label, race, SES,

\section{Focuson
Exceptional
children}

ISSN $0015-511 \mathrm{X}$ FOCUS ON EXCEPTIONAL CHILDREN (USPS 203-360) is published monthly except June, July, and August as a service to teachers, special educators, curriculum specialists, administrators, and those concerned with the special education of exceptional children. This publication is annotated and indexed by the ERIC Clearinghouse on Handicapped and Gifted Children for publication in the monthly Current Index to Journals in Education (CIJE) and the quarterly index, Exceptional Children Education Resources (ECER). The full text of Focus on Exceptional Children is also available in the electronic versions of the Education Index. It is also available in microfilm from Serials Acquisitions, National Archive Publishing Company, P.O. Box 998, Ann Arbor, MI 48106-0998. Subscription rates: individual, \$50 per year; institutions, \$68 per year. Copyright (C) 2012, Love Publishing Company. All rights reserved. Reproduction in whole or part without written permission is prohibited. Printed in the United States of America. Periodical postage is paid at Denver, Colorado. POSTMASTER: Send address changes to:

Love Publishing Company

Executive and Editorial Office

P.O. Box 22353

Denver, Colorado 80222

Telephone (303) 221-7333

\section{CONSULTING EDITORS}

Steve Graham Vanderbilt University
Ron Nelson

University of Nebraska-Lincoln

Eva Horn

University of Kansas

Carrie E. Watterson Senior Editor
Stanley F. Love Publisher neighborhood) dictates a priori what intervention will work. Nor will a given intervention be effective for all students of a particular group" (p. 160). Thus, the goal of data-based intervention decision making is to facilitate the individualization of services or interventions to each child's specific needs. This approach increases differentiation of early intervention services, which leads to intervention changes as soon as it is clear that a child is not making adequate progress (Chard et al., 2008; Division of Early Childhood, 2007; VanDerHeyden \& Burns, 2010). The "data" in databased decision making refers to progress monitoring data that (a) identify children who may be in need of support beyond what is universally available to all children, (b) measure the effect of additional supports or interventions for individual children, and (c) inform intervention changes for children who are not showing improvement (Carta, Greenwood, Walker, \& Buzhardt, 2010). Children who are not making expected gains receive more intensive or individualized intervention, the effects of which are evaluated with more frequent progress monitoring. Intervention strategies are then adjusted depending on the child's progress such that additional or more intensive strategies are used for children who continue to perform below expectations, and strategies that result in improved progress are maintained or reduced as needed (Greenwood et al., 2011). As early childhood programs increase their use of data-based intervention decisionmaking models (e.g., Response to Intervention [RTI], Recognition and Response, etc.), there is a corresponding increase in the need for tools to support efficient and effective management and interpretation of these data.

RTI, which utilizes a data-based decision-making approach, is a model that has gained increasing momentum over the past decade as a way to promote targeted, individualized support for children not making expected gains (Barnett, VanDerHeyden, \& Witt, 2007; Greenwood et al., 2011; Johnson, Mellard, Fuchs, \& McKnight, 2006; Walker, Carta, Greenwood, \& Buzhardt, 2008; Walker \& Shinn, 2010). Although there are a number of RTI variations (e.g., Coleman, Buysse, \& Neitzel, 2006; VanDerHeyden \& Burns, 2010), implementation is predicated on the availability of (a) technically sound progress-monitoring assessments that are curriculum based and sensitive to growth, (b) universal evidence-based practices available for all children, (c) evidencebased strategies for children not responding to universal practices, (d) decision-making criteria and benchmarks to inform when to move a child into or out of more intensive intervention, and (e) tools to support progress monitoring and the use of data to inform intervention decision making (Ball \& Trammell, 2011; Burns, Scholin, Kosciolek \& Livingston, 2010; Gresham, 2007; National Association of State Directors of Special Education, 2005). There is strong evidence to support the use of RTI and other decision-making 
models that utilize progress monitoring for school-aged children. For example, Burns, Appleton, and Stehower's (2005) meta-analysis of 24 studies of RTI models reported a large mean effect size (Cohen's $d=1.27$ ) favoring RTI models over comparison groups for student outcomes. Beyond the use of specific RTI approaches, the use of data to monitor students' progress and guide intervention decisions has also been shown to improve student performance in reading (Fuchs \& Fuchs, 2003; VanDerHeyden, 2005; VanDerHeyden \& Snyder, 2006) and math (Fuchs, Fuchs, Hamlett, \& Stecker, 1991).

\section{BARRIERS TO DATA-BASED DECISION-MAKING PRACTICES IN EARLY CHILDHOOD}

Despite support from federal policies such as No Child Left Behind and the Individuals with Disabilities Education Improvement Act, the use of progress monitoring and databased decision-making practices continues to be met with resistance by some in the $\mathrm{K}-12$ education community (Ball \& Trammell, 2011). When considering these practices for use in early childhood programs, additional barriers arise. Greenwood and his colleagues (2011) surveyed state coordinators of pre-K, Part B-619, and Head Start programs to identify challenges regarding the use of RTI in pre-K settings. These challenges included (a) workforce quality, (b) lack of knowledge and resources, (c) lack of evidence-based curricula and intervention strategies, and (d) limited administrative support. Similar challenges are faced by programs providing infant and toddler services and are likely magnified by an even greater lack of resources, fewer preservice training requirements, fewer measures to support infant and toddler progress monitoring, and the variation in which services are provided in home- or center-based settings.

Minimal training and professional development on how to use child data to individualize services and interventions is available to early childhood practitioners (Hojnoski, Caskie, Gischlar, Key, \& Barry, 2009; Linas, Carta, \& Greenwood, 2010). For instance, Sandall, Schwartz, and LaCroix (2004) surveyed early childhood practitioners serving children birth to 6 regarding their perspectives on the collection and use of child assessment data. Practitioners reported that they understood the potential value of using data for instructional planning but, in practice, used it very little or inconsistently because of challenges associated with data management and limited time. They also reported that the data that they did collect was rarely used because they lacked the knowledge, skills, time, and tools to make meaningful decisions based on the data. Similarly, the Roehrig, Duggar, Moats, Glover, and Mincey (2008) survey of kindergarten and first-grade teachers also reported challenges related to a lack of time and knowledge of how to use student data to inform literacy instruction. Some teachers reported a need for more time to work with teacher coaches or additional computer support to help them interpret individual children's data and inform instructional decisions. Infant and toddler service providers face similar constraints on their time and capacity to use data for intervention decision making, particularly those providing home- or community-based services that require substantial amounts of travel and the provision of services in environments with limited resources (e.g., the family's home or temporary housing) (Kelso, Fiechtl, Olsen, \& Rule, 2009).

Addressing these challenges through the use of computer or web-based systems has become more feasible as internet access increases, online data systems to manage child outcome data improve, and hardware and software costs continue to fall. For example, a number of innovative uses of technology to support early intervention and prevention services for young children have been explored over the past decade, including parent training and support (Baggett, Davis, Feil, Sheeber, \& Landry, 2010; Bigelow, Carta, \& Lefever, 2008; Hamad, Serna, Morrison, \& Fleming, 2010; Heitzman-Powell \& Buzhardt, 2011; Kelso et al., 2009; McCullough, 2001), practitioner training and professional development (Buzhardt \& Heitzman-Powell, 2005b; Dieker, Hynes, Hughes, \& Smith, 2008; Kinzie et al., 2006; Ludlow \& Duff, 2002; Powell, Diamond, \& Koehler, 2010; Vismara, Young, Stahmer, Griffith, \& Rogers, 2009), and child data management for accountability and program evaluation (Greenwood, Walker, Hornbeck, Hebbler, \& Spiker, 2007; Rous, McCormick, Gooden, \& Townley, 2007; Stedron, 2009). These applications are increasingly available to support service providers' knowledge of best practices, caregivers' ability to promote positive parent-child interactions and intensive interventions, and program directors' efforts to identify programmatic approaches that are working and those that are not. However, little empirical evidence exists to support the use of technology to improve the effectiveness or efficiency of data-based decision making practices.

\section{TO WHAT DEGREE IS COMPUTER-BASED TECHNOLOGY READY FOR USE IN THE FIELD BY EARLY CHILDHOOD PRACTITIONERS?}

For the closing keynote address at the 2011 conference of the International Society for Education Technology, Chris Lehmann asserted that education has moved from asking can technology be integrated into education to how to integrate technology into education (2011). Over the past decade, lower costs and advances in technology hardware and software and improved usability have expanded the reach of advanced applications from the wired offices of computer enthusiasts to the hands of anyone with access to an internet 
connection or a cellular data plan. The latest Pew Internet Project data show that internet usage among adults in the U.S. has increased from 13\% in 1995 to $77 \%$ in 2010 (2011). Home broadband access (e.g., cable or DSL modem), which is required to take full advantage of most advanced webbased applications, has risen from about 3\% in 2000 to $66 \%$ in 2010 (Pew Internet Project, 2010). Access to the internet via mobile devices is also sharply increasing: $83 \%$ of all adults in the U.S. use a cellphone, and $42 \%$ of those use a smartphone (e.g., iPhone, Android, or Blackberry) with internet access, email, and text messaging (Pew Internet Project, 2010).

Despite this exponential growth in technology access, questions remain about equitable access among minorities and disadvantaged populations. Although this "digital divide" still exists, it is much less pronounced than it was 20 years ago. For example, in just one year from 2009 to 2010 , adoption of broadband internet access grew by only $3 \%$ among White Americans, while African Americans' access grew 22\% (Smith, 2010a). This is the smallest reported gap between Whites and Blacks in terms of broadband access ( $67 \%$ versus $56 \%$, respectively) since such data have been collected. There is also evidence that the digital divide is becoming more of a "digital variation" in that different cultures access the internet and use technology somewhat differently. For example, of those who use the internet, $51 \%$ of Hispanics and $46 \%$ of African Americans access it with a mobile phone, compared to only $33 \%$ of White Americans. Furthermore, minorities are more likely to use their mobile phone for a wider range of purposes than Whites: Over $80 \%$ of all African Americans and English-speaking Hispanics use texting, compared to only $68 \%$ of Whites (Smith, 2010b).

The current trend in the technology industry is to develop advanced applications that are accessible over the web and require no more than an internet connection and modern web browser, diminishing the need for high-end hardware. By 2008 , nearly $100 \%$ of public schools in the U.S. had internetenabled computers used for instructional purposes, and $87 \%$ of schools used web-based applications to access standardized assessment data for instructional planning and individualization (U.S. Department of Education, 2010). A survey of 1445 early childhood educators (infant/toddler, preschool, and $\mathrm{K}-3$ ) found that $80 \%$ report using the internet every day, $94 \%$ report using it to find educational activities to use with their children in the classroom or home, and 94\% rate themselves as "successful" or "very successful" in their ability to use the internet (Wartella, Schomburg, Lauricella, Robb, \& Flyenn, 2010). Unknown is the degree to which these practitioners use the internet or web-based applications for instructional planning and data-based decision making.

These technology improvements, increased technology acceptance, and federal policy mandates for the integration of technology into existing curricula (e.g., U.S. Department of Education, 2002) has led to the ubiquitous use of computers in nearly every public school in the U.S. either for instruction, data management, or both. Although thousands of studies have investigated the effectiveness of computerassisted instruction, there has been very little empirical research that investigates the impact of computer-based tools to support progress monitoring and data-based decision making. Therefore, in the next section, we will describe some of these existing tools, and, given the lack of research on these tools for education, we explore the lessons learned from the medical community's 40 years of investigating the use of computer-based decision support systems (CDSSs).

\section{THE USE OF TECHNOLOGY TO SUPPORT DECI- SION MAKING IN EDUCATION AND MEDICINE}

Over the past decade, assessment developers have recognized the need for technology that aids teachers' management and interpretation of assessment data, particularly those that are frequently administered and used in a databased decision making framework. Examples of these webbased applications for progress monitoring and instructional planning include the online data system for the Dynamic Indicators of Basic Early Literacy Skills (DIBELSC) to monitor $\mathrm{K}-8$ literacy progress; the AEPSinteractive (C) webbased tools to manage and report results for the Assessment, Evaluation, and Programming System (AEPS); the iSTEEPC) online data management system to support $\mathrm{K}-6$ math and literacy progress monitoring and decision making using the STEEP assessment; the AIMSWebC progress monitoring system that supports a range of $\mathrm{K}-12$ behavior and academic outcomes (e.g., math, reading, spelling, early literacy, and writing); and the Infant and Toddler Individual Growth and Development Indicators (IGDIs) online data system to support progress monitoring for children 6-36 months old.

In $\mathrm{K}-12$ education, tools such as AIMSWeb, Wireless Generation's mCLASSC, and DDtracC allow teachers to enter or import child data into a software or web-based system, which provides tools that display and/or describe the data to inform intervention decisions and instructional planning. Wireless Generation (2008), a commercial developer of software that supports classroom assessment with mobile devices, reports that their mCLASS solutions software is used with more than 2 million K-12 students in 49 states. Teachers can use $\mathrm{mCLASS}(\mathrm{B})$ to assess children in reading (DIBELS, TPRI, Reading Records, and Tejas LEE), preschool social-emotional development (CIRCLE), and math. Pearson's AIMSweb is a web-based progress-monitoring and decision-making tool that can be used to identify children in need of more intensive instruction in literacy and math, as well as providing individualized Tier 2 and 3 recommendations 
based on student performance. AIMSweb was recently adopted by the Clark County School District in Nevada to support progress-monitoring and decision making of more than 200,000 elementary and middle school students (AIMSweb, 2011). DDtrac (Gregg, 2009) is a web-based system that supports the planning of goals and objectives for students' individualized education plans (IEPs) and subsequent monitoring of progress toward achieving those goals. As part of the Infant and Toddler IGDI online data system, the web-based Making Online Decisions (MOD; Buzhardt et al., 2010) guides infant and toddler service providers through a data-based intervention decision-making process for children performing below normed benchmarks in expressive communication and provides individualized Tier 2 intervention strategies. This system is described in greater detail later.

The apparent benefits of using these computer-based tools include improved instructional decision making, time savings in terms of managing and graphing data, dynamic reports to share with parents and other teachers, the ability to compare performance between groups, and tools to merge data from other systems. These benefits, which are usually illustrated through testimonials on websites and other marketing materials, are expected to lead to the ultimate goal of earlier identification of children in need of more intensive intervention, instruction that is more responsive to each child's unique needs, and improved student outcomes. However, with the exception of a peer-reviewed report of the DDtrac system's usability (Gregg, 2009) and a recent randomized trial of the Infant and Toddler IGDI MOD system (Buzhardt et al., 2011), we are aware of no empirical investigations of these tools that compare their use to traditional decision making without computer support. Although technology costs have come down and educators are more accepting of technology, the field of education and special education would be remiss not to investigate basic questions such as whether these tools actually improve instructional decision making, and, if they do, what components have the most impact and under what conditions. Indeed, the field of medicine has extensively researched the impact of CDSSs on medical professionals' decision making and patient outcomes, and the results are not always favorable toward CDSSs (Classen, 1998; Ahmadian et al., 2011).

There are several parallels between the data-based decision-making and progress-monitoring processes used in education and those used by medical professionals (Gresham, 2007). Each time a patient visits a physician, brief assessments or diagnostic exams of general health are performed (e.g., blood pressure, weight, temperature, etc.), as well as documentation of the patient's answers to general health questions. Patients who fall outside of the normed benchmarks on the assessments may receive additional, more invasive assessments and questioning specific to the patients' concerns. Depending on the results of the assessments and how far the results fall outside of expected values, the physician will likely recommend a minimal treatment (e.g., change in diet, more exercise, or a mild medication) and schedule a follow-up visit in the near future to monitor the patient's progress. Based on the patient's progress and the results of future assessments, the physician will either maintain the existing treatment, decrease its intensity or dosage, increase it, or remove it all together. For patients whose condition is not responding to treatment, the frequency of progress monitoring may increase (e.g., in-patient care) in order to quickly assess the effect of treatment changes.

Similar to teachers who use data to make decisions, physicians must also manage large amounts of data, interpret those data, and make complex choices based on those interpretations. Unlike education, however, CDSSs have been available to facilitate data-based medical decision making for nearly 40 years. Informed by physician input and patient inquiry, CDSSs can provide recommendations for diagnostic tests, questions to ask patients, recommended prescriptions, drug dosages, and so on. Garg and his colleagues' (2005) review of more than 100 controlled trials of CDSSs found that physician decision making improved in $64 \%$ of the studies that measured decision making. Findings were much less promising regarding the impact of CDSSs on patient outcomes: Only 7 of the 52 trials found improved patient outcomes compared to those without CDSS support. Most interesting and relevant to CDSSs in education is that effectiveness was found to be mediated by CDSS features that directly influence practitioners' decision making and the setting in which they are used. For example, CDSSs were more likely to be effective in improving practitioner performance if the CDSS (a) automatically prompted the practitioner regarding next steps rather than requiring the practitioner to manually request next steps, (b) had an intuitive and usable interface that garners high user satisfaction ratings, (c) could be integrated into existing workflow patterns, and (d) had administrator buy-in to support its ongoing use (Garg et al., 2005; Hunt, Haynes, Hanna, \& Smith, 1998; Kawamoto \& Lobach, 2003).

Because the use of CDSSs are a relatively new facet of special education, we should heed the message from the medical literature that simply putting a computer-based decision-making tool into the hands of teachers does not guarantee success. Research is needed to identify the critical features of CDSSs that lead to improved decision making and student outcomes. This is particularly important for ECSE, where access to computer resources is limited and support for frequent standardized assessments, although growing, is less common than in the $\mathrm{K}-12$ community. 
These issues are even further compounded for infant and toddler services specifically, where there are few available progress monitoring assessments and even less with computer-based tools to support data-based decision making. However, in the next section, we describe one set of infant and toddler progress monitoring assessments that include computer-based support to manage, interpret, and guide decision making, as well as empirical support for its use.

\section{HOW ARE INFANT AND TODDLER IGDIS USED FOR INTERVENTION DECISION MAKING, AND WHAT IS THE EVIDENCE TO SUPPORT THEIR USE OF TECHNOLOGY?}

Perhaps one of the most powerful instruments that practitioners have to support their intervention efforts is an efficient and effective way to measure how a child is responding to an intervention. However, infant and toddler service providers (e.g., Part C, Early Head Start, Parents as Teachers, etc.) often lack the appropriate measures to effectively assess children's strengths and needs during these first years (Neisworth \& Bagnato, 2004). Most existing measures of infant and toddler abilities are notoriously poor predictors of later development (Gibbs \& Teti, 1990), and, although measures are beginning to emerge, there remain a limited number of psychometrically sound measures that have been demonstrated to be effective for progress monitoring and intervention decision making.

Infant and toddler progress monitoring measures with known psychometric properties and web-based tools to support data management and intervention decision making include the AEPS, the Infant and Toddler Child Observation Record (COR), and Infant and Toddler IGDIs. Both the COR and AEPS are classic examples of "authentic assessments" that do not have age-based normative benchmarks, and, rather than adhering to strict administration guidelines, child data are collected within the child's natural environment during daily activities with familiar adults and peers (Grisham-Brown, Hallam, \& Brookshire, 2006). Each of these measurement systems has sound psychometric properties (Bricker \& Pretti-Frontczak, 1997; Greenwood et al., 2008; High/Scope Educational Research Foundation, 2005) and has been demonstrated to be effective in informing intervention decision making and instructional planning (Bricker, Yovanoff, Capt, \& Allen, 2003; Buzhardt et al., 2011; Fantuzzo \& Yumiko, 2005; Madigan, n.d.; Notari \& Bricker, 1990; Weikart, 2004). They also have web-based tools that facilitate data interpretation for early identification of children in need of intervention and progress monitoring of child response to intervention. In addition, the online data system for Infant and Toddler IGDIs has empirical evidence to support its use for intervention decision making. Therefore, in the following section, we describe the Infant and Toddler IGDIs, the web-based system to support intervention decision making, the research to support the technology's use, and how this research can be used to inform future advancements in technology-supported databased decision making.

\section{INDIVIDUAL GROWTH AND DEVELOPMENT INDICATORS FOR INFANTS AND TODDLERS}

Individual Growth and Development Indicators are psychometrically sound measures designed for frequent, brief assessments of growth toward general outcomes (Parrish \& Phillips, 2003; Snow \& Van Hemel, 2008). Infant and Toddler IGDIs (Carta et al., 2010) are play-based assessments designed and normed to measure infant and toddler growth from 6 to 40 months across five domains: Communication (Early Communication Indicator: ECI), Social Engagement (Early Social Indicator: ESI), Problem Solving (Early Problem Solving Indicator: EPSI), Movement (Early Movement Indicator: EMI), and Parent-Child Interaction (Indicator of Parent-Child Interaction: IPCI). Individual studies were conducted for each of the five measures to document their psychometric properties and feasibility, including identification of standard toy sets and longitudinal studies demonstrating their sensitivity to growth over time and short-term early interventions (ECI: Greenwood, Walker, \& Buzhardt, 2010; EMI: Greenwood, Luze, Cline, Kuntz, \& Leitschuh, 2002; ESI: Luze et al., 2001; EPSI: Greenwood, Walker, Carta, \& Higgins, 2006; IPCI: Baggett \& Carta, 2006). To support the use of Infant and Toddler IGDIs for ongoing progress monitoring, a website and online data system are available to generate dynamic individual child progress graphs, group reports of child data for program accountability, and an intelligent system to guide service providers through a data-based decision-making process for children falling below established benchmarks (Buzhardt et al., 2010).

For each IGDI, an observer codes a set of behaviors or "key skill elements" during a 6-minute session in which the child engages with a standard set of toys with an adult play partner. The adult play partner facilitates the child's play by following his or her lead, commenting and labeling about what the child is doing, and maintaining the child's interest in the activity without being directive (Buzhardt \& Walker, 2010). Key skill elements demonstrated by the child are coded by a certified assessor, either live or by watching a video recording of the session. For example, during an EMI assessment, the assessor codes the following key skill elements according to a detailed set of operational definitions: Catching/Trapping, Transitional Movements, Grounded Locomotion, Vertical Locomotion, and Throwing/Rolling. After 
coding an assessment on a standard paper scoring form, the assessor enters the key skill element frequency counts for each minute into the IGDI online data system.

\section{Web-Based IGDI Tools to Inform Intervention Decision Making}

Practitioners who are trained and certified to administer and code IGDIs (Buzhardt \& Walker, 2010) receive an account within the secure, password-protected IGDI online data system (www.igdi.ku.edu) to enter and manage their IGDI data. After entering their scores into the data system, they can generate graphs of the child's total performance across all key skill elements or performance on individual key skill elements. Figure 1 shows an example of the Weighted Total Communication graph for the ECI. This graph plots the child's assessments according to the child's age in months (x-axis) and calculated total weighted communication per minute (y-axis). For the ECI, the weighted score per minute is calculated by summing the key skill elements (Gestures, Vocalizations, Single Words, and Multiple Words) and dividing by six or the number of minutes that the assessment lasted. The weighting is achieved by multiplying the total single words by two and total multiple words by three. The online data system performs all of these calculations automatically based on the raw frequency counts entered by the assessor. Graphs can also be generated to show the child's performance on each key skill element relative to established norms for each.

Use of any data-based decision-making model requires resources to manage and analyze data as well as training in how to interpret and act on data - training that infant and toddler service providers often lack (Hojnoski et al., 2009; Sandall et al., 2004). The graphing and data management capabilities of the IGDI online data system, as well as those of the AEPS and OnlineCOR, are designed specifically to reduce the demand on practitioners' time to manage and analyze assessment data. The graphs, along with other features of the IGDI data system, were tested and revised based on feedback from usability testing trials with early childhood professionals to optimize the system's utility for practitioners with limited experience or training in interpreting data (Buzhardt et al., 2007).

In addition to providing resources to interpret individual child data, the system provides administrator functions to monitor programwide outcomes. Figure 2 shows sample aggregate graphs of all children's recent scores in an entire program, providing a snapshot of children's communication for each key skill element and weighted total communication

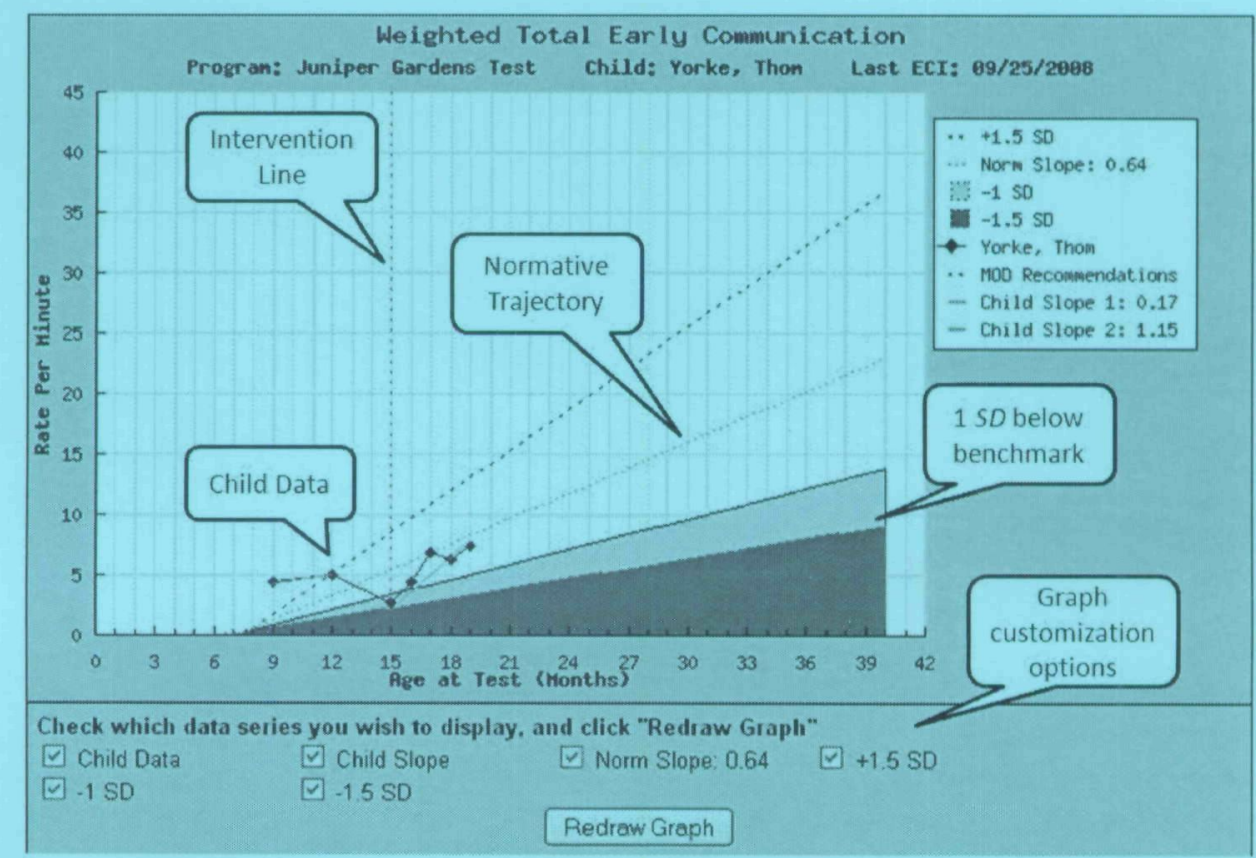

FIGURE 1.

A sample Weighted Total Communication progress-monitoring graph for the Early Communication Indicator generated by the Infant and Toddler IGDI online data system 
Average Trend in Key Skill Elements for Children in the Program
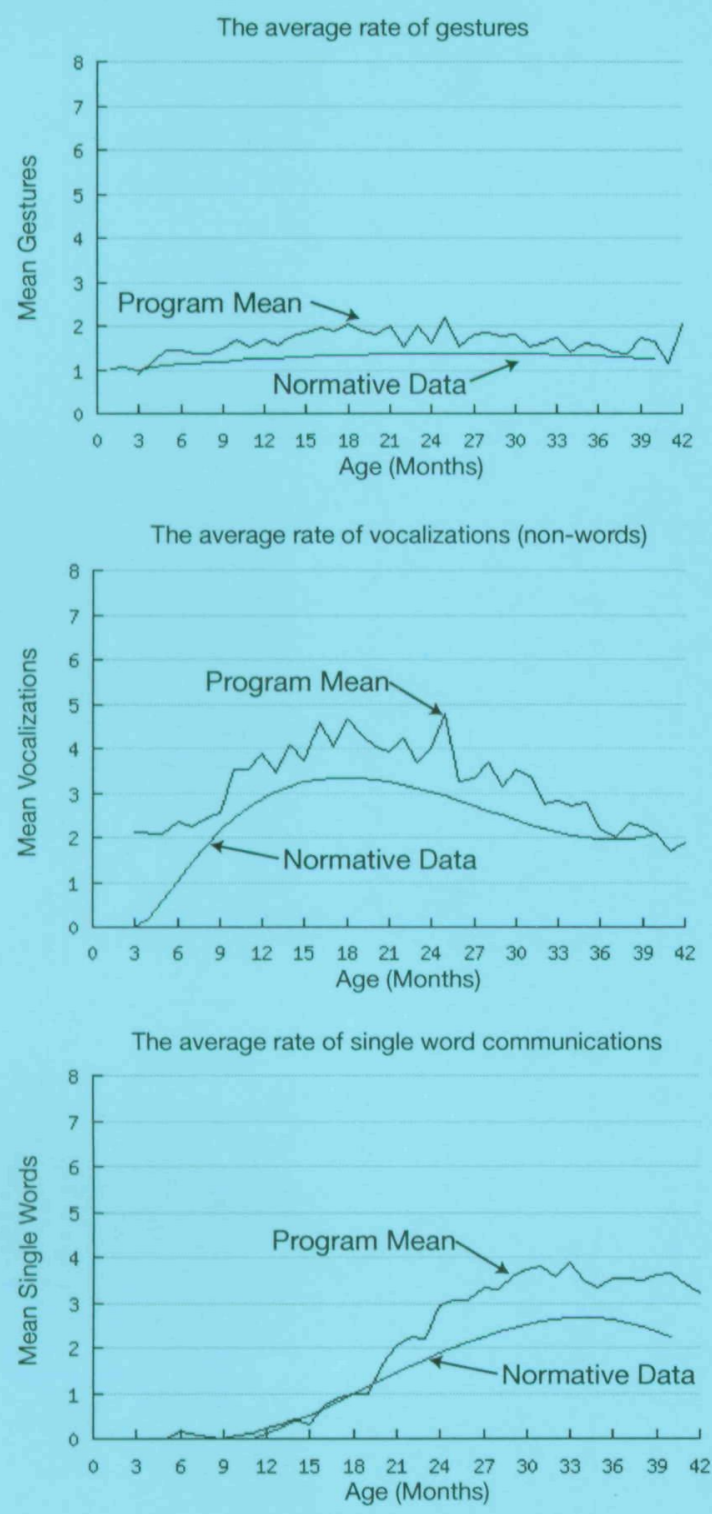

The average rate of multiple word communications

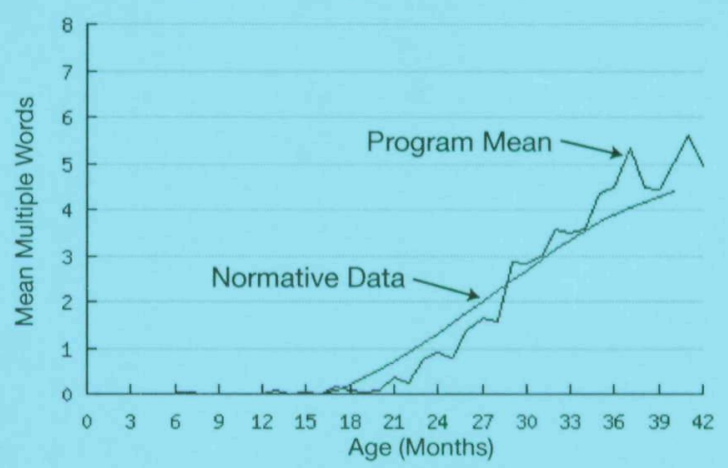

The final graph illustrates average growth in children's rate of weighted total communication with gestures, vocalizations, single words, and multiple words combines.

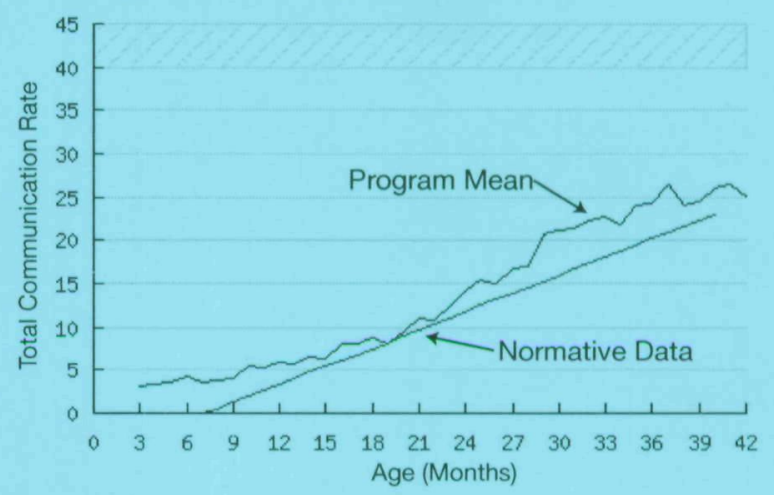

\section{FIGURE 2.}

\section{Graphs of children's aggregated performance on the Early Communication Indicator within a program (available through the IGDI online data system)}

against expected norms. Other administrator resources include child demographic reports, assessor certification results, and alerts that identify children whose recent performance indicates a potential concern and a direct link to the child's data. As of this writing, more than 35,000 infant and toddler assessments have been entered into the online IGDI data system, nearly 12,000 infants and toddlers have been assessed, and there are approximately 1,500 registered users (e.g., certified assessors, program coordinators, data entry staff, etc.) across 20 states and three countries. The website receives an average of 1,500 unique visitors each month.

For programs that seek additional guidance in using ECI data for language intervention decision making, an "intelligent advisor" is available called the Making Online Decisions (MOD) system (Buzhardt et al., 2010; Buzhardt et al., 2011). Similar to CDSSs used in medicine, the MOD is 
designed to guide practitioners through a data-based decision-making model similar to the IGDI problem-solving model (Walker et al., 2008) and founded on Tilly's (2008) problem-solving model. Integrated into the IGDI online data system, the MOD is an optional feature that can be engaged for an entire program or for specific service providers within a program. Figure 3 provides an overview of the MOD decision-making process, which is guided by five key questions:

1. Is there a problem? For children whose ECI score is at least $-1.0 \mathrm{SD}$ below their age-based norm, the MOD automatically generates the child's growth chart and asks the service provider to validate the child's low performance (i.e., confirm that it was a valid administration of the assessment).

2. What is causing the problem? A list of clinical issues linked to poor progress is presented by the MOD and ruled in or out by the service provider.

3. What intervention(s) should be used? The MOD recommends language-promoting strategies individualized to the child's performance on ECI key skill elements. The service provider shares these with caregivers, who are taught to use them with their child during daily routines. These strategies are derived from The Strategies for Promoting Communication and Language of Infants and Toddlers (Walker, Bigelow, Harjusola-Webb, Small, \& Kirk, 2004) and the Language Intervention Tool Kit (Crowe, 2002; also see www.ku.igdi.edu/internventions/ECI_interventions.htm).

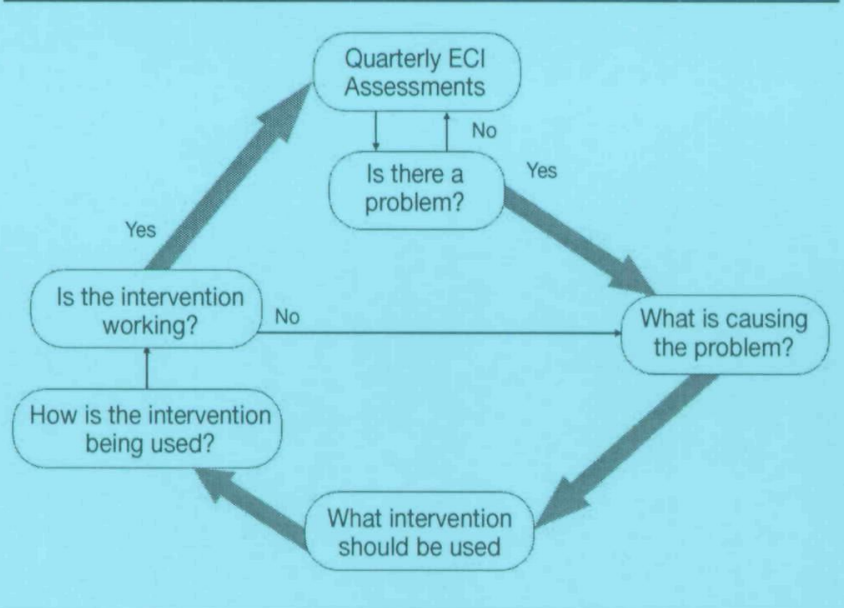

FIGURE 3.

The data-based intervention decision making model for the Making Online Decisions system (adapted from Tilly, 2008)
4. Is the intervention being done? Using fidelity of implementation checklists generated by the MOD, service providers document their work with caregivers in teaching them the strategies and enter it into the MOD. They also document the caregivers' reported frequency of use of the strategies.

5. Is the intervention working? After three ECIs following intervention, the MOD analyzes child total communication before and after intervention; and, given a lack of improvement, the intervention is revised, and the cycle repeated.

After analyzing the ECI data, the MOD immediately generates a recommendation for the service provider. For example, for a child who is performing within age-based expectations after intervention, the MOD would generate the following recommendation (taken verbatim from the MOD):

\footnotetext{
As you can see by Beth Majure's graph, it appears that she is within benchmark and, based on the slope, will likely remain above benchmark. This is great news! We recommend that the family continue with the strategies they've been using, but for now, you can stop entering the fidelity checklist data, and you can return to conducting quarterly ECI observations with Beth.

As Beth's language continues to improve, we will continue to recommend new strategies that will help maintain this progress. We recommend that you print these strategies and give them to the family or use them along with your regular home visiting program, but you will not need to record how much they are using the strategies.

If Beth's ECI scores begin to fall below benchmark again, we will recommend returning to monthly monitoring and doing the follow-up checklists again.
}

\section{Evidence to Support the Use of Technology with Infant and Toddler IGDIs}

A randomized control trial of the MOD with Early Head Start (EHS) home visitors was recently reported (Buzhardt et al., 2011). Home visitors from five Kansas EHS programs were randomly assigned within programs to either use the web-based MOD system or continue without MOD support. Twenty-six home visitors used the MOD, and 22 were nonMOD. Sixty-three of the MOD home visitors' children received MOD services because they fell at least 1 SD below benchmark, while 61 children from the non-MOD home visitors' caseloads fell below benchmark. In summary, those children whose home visitors used the MOD demonstrated significantly stronger growth on the ECI than children who received non-MOD services. Cohen's $d$ indicated medium effect sizes. Also, home visitors reported high satisfaction ratings for each component of the MOD.

Although this study suggests that the MOD's web-based support and individualized intervention recommendations can have an impact on child outcomes, additional research is 
needed to further explore how the MOD impacts service providers' data-based decision-making practices. For example, does the MOD facilitate a faster response to children's low performance? Are more frequent changes to the intervention strategies made for children who are showing little or no improvement? How does the MOD influence parent/caregiver use of family-centered intervention? Are there cost savings for using the MOD relative to no computer support for intervention decision making (e.g., ongoing professional development or coaching)? And what characteristics of service providers and their programs moderate the MOD's effectiveness (e.g., technology experience, education background, administrative buy-in for the MOD, available technology resources, etc.). These questions and others are critical to designing CDSSs that address the unique challenges faced by programs that provide in-home or center-based early childhood services. However, integrating technology into established practices can often result in new challenges. Therefore, in the next section, we discuss some of the challenges to using CDSSs that have been researched in other areas and how they can be addressed.

\section{WHAT CHALLENGES HAVE BEEN IDENTIFIED IN THE USE OF TECHNOLOGY TO SUPPORT PROGRESS MONITORING AND DECISION MAKING IN K-12 EDUCATION AND MEDICINE?}

The tools to support progress monitoring and data-based decision making for infants and toddlers are beginning to proliferate, but they have yet to gain large-scale use relative to the measures and tools available for $\mathrm{K}-12$ education (Linas, Carta, \& Greenwood, 2009; Greenwood et al., 2008). We also know that incorporating a new technology into existing education practices can introduce challenges of its own, such as the need for additional professional development and technical support, as well as a lack of buy-in from practitioners if there is not a clear link between the technology and child or student outcomes (Buzhardt \& HeitzmanPowell, 2005a; Dell, Newton, \& Petroff, 2011). If one goal of using technology to support progress monitoring and databased decision making is to minimize the hurdles associated with these practices, then it is necessary that the challenges introduced by the technology itself do not outweigh the potential benefits. The success of individual CDSS applications will ultimately vary depending on the degree to which challenges are minimized and benefits are maximized.

Despite widespread adoption of technology that supports data-based decision making in $\mathrm{K}-12$ education (e.g., DIBELS, AIMSWeb, etc.), little is known about how these supports affect educators' instructional planning and child outcomes. However, as described earlier, the field of medicine has identified several issues that are relevant to the use of computers to support progress monitoring and intervention decision making in education. Additionally, through our team's experience in supporting the use of the IGDI online data system over the past 6 years, usability testing, and a randomized trial, we have identified challenges and issues to consider that are similar to those in the field of medicine as well as some that may be unique to early childhood. These issues can be classified into two general areas: (1) seamless integration into existing practices and service delivery models and (2) ensuring usability in a variety of settings.

\section{Seamless Integration into Existing Practices}

Integrating new practices into existing service delivery and educational settings, with or without the use of technology, requires consideration of current practice, practitioners' experience and training, and administrative supports and incentives, among other issues (Carnine, 1997; Dell, Newton, \& Petroff, 2011; Elmore, 1996; Greenwood \& Abbott, 2001; King-Sears, 2001). In the medical profession, the ability to integrate CDSSs into existing patient care and health service delivery models is a significant factor in the adoption and ultimate effectiveness of CDSSs (Ahmadian et al., 2011; Garg et al., 2005; Moxey et al., 2010). Factors that contribute to successful integration vary considerably depending on the goals of individual CDSS applications (e.g., improve diagnostic accuracy, prescription or dosage recommendations, patient compliance with physician recommendations, etc.) and individual clinical settings. However, in a recent survey of CDSS developers, $92 \%$ of respondents reported that the most common barrier to CDSS implementation was related to data management: Higher data management demands decreased the likelihood of sustained adoption (Ahmadian et al., 2011). Other studies have investigated the impact of increased data-entry demands and found that as data-entry and management demands increase, physician acceptance decreases (Margolis et al., 1992; Nilasena \& Lincoln, 1995). Based on their review of the CDSS literature and implementation barriers, Ahmadian and her colleagues (2011) asserted that "physicians are not willing and do not have time to interact with a system that requires them to do more work" (p. 88). This statement reflects the constant struggle to balance best practice with growing caseloads and increased accountability - a reality that is certainly familiar in early childhood education. Therefore, it is important that data management activities are consolidated whenever possible (e.g., using progress monitoring data to inform intervention and to support accountability reporting requirements).

Early childhood programs have been pressed to consider their assessment practices in light of current mandates for state- and federally-funded early childhood programs to collect and report data on their overall impact on child outcomes 
(Greenwood et al., 2007; Hebbeler, Barton, \& Mallik, 2008; Horton \& Bowman, 2002). For example, the Office of Special Education Programs (OSEP) requires that Part C (infant and toddler) programs provide annual reports of the percentage of children who demonstrate improvements in the following outcome areas (National Early Childhood Technical Assistance Center, 2008):

1. Positive social emotional skills

2. Acquisition and use of knowledge and skills

3. Use of appropriate behaviors to meet their needs

Unfortunately, a limited number of assessments are designed specifically to measure and report program effectiveness (Hebbeler et al., 2008). Also, administering one set of assessments to measure program effectiveness and another set for progress monitoring and intervention decision making potentially leads to an excessive amount of assessment.

Like CDSSs that integrate with existing health information systems (Ahmadian et al., 2011), CDSSs that support infant/toddler services should be able to draw from programs' existing accountability data systems to inform intervention decisions, or at least they should provide tools that allow administrators to convert or export data entered into the CDSS into systems used for accountability reporting. This minimizes the amount of time spent on data entry and management, thereby increasing time available for service delivery. Although the measures and tools used to meet the OSEP reporting demands vary by program and will likely continue to evolve in the coming years, in order to increase the likelihood of wide-scale adoption, CDSSs should be designed in such a way that recognizes these existing data demands. For example, both the Infant and Toddler IGDI online data system and the OnlineCOR provide online administrator tools that generate dynamic reports of children's progress toward proficiency in at least one of the three OSEP outcome areas. However, it is currently unknown how many programs use these tools to support their accountability reporting efforts.

Although we can learn from medical research on CDSSs, more research is needed to identify factors that facilitate the integration of CDSSs into existing early childhood practices. One such factor, usability, has been found to play a major role in the successful adoption and integration of technology-supported practices. In the next section, we explore the potential impact of a CDSS's usability on its ability to affect practice.

\section{Ensuring Usability in a Variety of Contexts}

A key recommendation of Carnine's (1997) proposal for increasing the demand for evidence-based education practices is for researchers to develop practices that are not only effective under tightly controlled conditions but also usable within natural education settings. The degree to which a CDSS can be integrated into service providers' current practices with children and families is dependent on the system's usability by users with a range of technology experience and its accessibility on a variety of common computer platforms. Ongoing federal initiatives encourage and support research into the effectiveness of evidence-based practices under natural conditions. For example, the Goal Four competition for the Institute of Educational Sciences' Special Education Research Grants funds research that explores interventions "implemented under conditions that would be typical if a school district or other education delivery setting were to implement them" (Institute of Education Sciences, 2011, p. 56). Technology developed under OSEP's Steppingstones of Technology Innovation for Children with Disabilities "must include a formative evaluation of the technology-based approach's usability and feasibility for use with children with disabilities" (OSEP, 2011, p. A-7). However, with few exceptions, formal usability testing of educational technology that goes beyond self-reported user satisfaction is rarely reported.

Usability testing that includes direct observations of users engaging with the technology, preferably under natural conditions, is the most effective for identifying ways to design more intuitive user interfaces and streamline procedures for completing tasks with the technology (Barnum, 2002; Nielsen, 1993). Direct observation is preferable to self-report and satisfaction surveys because it diminishes the potential for bias due to social desirability factors (e.g., participants wanting to please the researcher or developer). For example, in a study of the usability of the ClassWide Peer Tutoring Learning Management System, Buzhardt, Abbott, Greenwood, and Tapia (2005) found that although $80 \%$ of teachers rated the system as "easy" or "very easy" to use, $40 \%$ needed help or reported a problem completing at least one common activity with the system. Despite few published reports of direct observation usability testing of education or special education technology, several examples in commercial industries reveal significant reductions in training and time to complete tasks (Gibbs, 1997), increased adoption of practices (Usability Professionals' Association, 2011), and reduced error rates (Barnum, 2002) as a result of system improvements informed by this type of usability testing.

The usability of CDSSs in the medical profession can have life-or-death implications. In a direct observation usability study of a CDSS for emergency physicians, Graham and his colleagues (2008) found that flaws in the user interface resulted in five incorrect physician decisions (out of 422), three of which had life-threatening consequences. These errors have been called technology induced errors (Kushniruk, 
Triola, Stein, Borycki, \& Kannry, 2004). Although these decision errors in early childhood education may not have the immediate consequences experienced by emergency physicians, failure to correctly identify a child in need of early intervention or inappropriate intervention recommendations could have long-term impacts on that child's school readiness and future success in school (Administration on Children Youth and Families, and Head Start Bureau, 2002; Love, 2005; Raikes et al., 2006; Shonkoff \& Phillips, 2000; Snow \& Van Hemel, 2008). Considering the findings from the medical CDSS literature and the limited resources and technology training often available to early childhood programs, optimizing the usability of individual CDSSs for use in early childcare settings should be a key goal of CDSS research and development efforts.

For the Infant and Toddler IGDI online data system, direct observation usability testing was conducted onsite at 14 Early Head Start programs throughout Kansas and Missouri with local service providers. During testing, an assessor asked participants to complete 30 common tasks using the system, such as generating a progress-monitoring graph, interpreting a child's data, and entering assessment data (Buzhardt et al., 2007). An observer recorded the time it took for each participant to complete each task and documented all tasks in which the participant requested help. Data entry was identified as the most time-consuming task ( 2.5 minutes per assessment) and most prone to error. This is consistent with the findings of the medical CDSS literature identifying increased data-management and entry demands as significant barriers to implementation (Ahmadian et al., 2011). Thus, informed by usability testing, data-entry interfaces were modified to reduce the number of "clicks" required to enter data and to automatically check for and warn users of potential data entry errors (e.g., incorrect assessment date or a score that would be an extreme outlier).

Because progress-monitoring graphs must be easy to interpret for intervention decision makers with little or no training (Codding, Skowron, \& Pace, 2005; Hojnoski et al., 2009), service providers were also asked to generate and answer questions about the progress-monitoring graphs produced by the data system. Although $80 \%$ or more of the service providers correctly answered questions about the graphs (e.g., What is this child's slope or average rate of growth after the latest intervention change? How does this child's latest assessment compare to the norm for his or her age?), they provided suggestions for improving readability. For example, the areas indicating 1 and 1.5 standard deviations below the norm performance were highlighted in grey and dark grey (see Figure 1) to easily identify children who may be in need of more intensive intervention.

The field of education and special education has long focused on the efficacy of interventions and their impact on child outcomes under controlled conditions and with significant training, support, and oversight by developers and researchers. The field has been less adept at preparing interventions for implementation beyond the reach of researchers (Elmore, 1996; Fuchs \& Fuchs, 1998). As early childhood special education continues to increase the use of technology, an ongoing challenge is designing applications that can be used with little or no training while providing maximum functionality (Rubin \& Chisnell, 2008). For tools such as CDSSs in which technology is a key component, usability testing with the target population under natural conditions is vital to successful integration, scale-up, and, ultimately, its impact on child outcomes.

\section{HOW CAN MOBILE DEVICES SUPPORT PROGRESS MONITORING AND INTERVENTION DECISION MAKING?}

By definition, the Internet is a network of computers and other devices that share data, which makes it an obvious fit to support data-based practices. As Internet use increases and the variety of devices with which we access it continues to expand, how we use it to support these practices will continue to evolve. Perhaps the leading technology trend with the most significant implications for early childhood progress monitoring and decision making is the exponential proliferation of low-cost internet-enabled mobile devices (e.g., smartphones, tablets, netbooks, etc.) Given current trends, industry analysts estimate that by 2014 more people will access the internet with a mobile device than a desktop computer (Ingram, 2010).

The ability to access web-based CDSS tools with devices that can go "on the road" is particularly relevant for infant and toddler services that are often provided in homes or other natural settings beyond a centralized classroom or center. Part C of IDEA stipulates that early intervention services be provided within the child's "natural environment." Although the natural environment can be broadly interpreted, early intervention services in many early childhood service delivery models (e.g., Early Head Start, Part C) involve some form of home visitation, with approximately 500,000 families receiving some form of home-based services in the U.S. (Astuto \& Allen, 2009). However, home visiting models present unique challenges to implementing best practices in progress monitoring and data-based decision making. Unlike school settings, in which teachers and interventionists often have access to computers and internet resources for immediate data entry and analysis, home visitors must conduct their assessments during relatively brief visits (1-2 hours a week) under a variety of conditions. Coding and interpretation of progress-monitoring data then occurs at the service provider's office, using a desktop computer at some 
point removed from the home visit. If the assessment is coded in a timely manner, the results can be shared with the caregiver at the next home visit-often at least a week or more after the assessment was administered, depending on the program's home visiting schedule. This results in a natural delay in the onset of intervention delivery or modification of interventions that are not working.

Compounding the need for service providers to receive information at the point of care (e.g., in families' homes during home visits or centers with limited computer resources) is the primary caregiver's critical role in intervention planning and delivery for infants and toddlers (Dunst, Bruder, Trivette, Hamby, 2006; Odom \& Wolery, 2003; Weiss, Caspe, \& Lopez, 2006). In this context, intervention often involves adjusting the child's natural environment to promote positive behavior change. Because the primary caregiver (e.g., parent or relative) plays a key role in the child's natural environment, he or she also becomes a primary facilitator of the intervention. Immediately sharing data with parents using a mobile device and involving them directly in the intervention planning process may increase their sense of ownership in intervention decisions and the likelihood that they will implement the recommendations. The use of mobile devices to support early interventionists' timely use of progress-monitoring data for intervention decision making at the point of care can potentially lead to earlier intervention implementation and stronger collaboration with families in these contexts.

A number of $\mathrm{K}-12$ progress-monitoring measures have software to support their use with mobile devices (e.g., Wireless Generation's mCLASS series of tools and AIMSweb Palm Link). Although the field needs empirical support for the use of mobile devices in progress monitoring and decision making, anecdotal evidence suggests that teachers who use mobile devices prefer them over pen and paper and recognize their potential benefits. For example, teachers have reported that using mobile devices for DIBELS data collection decreases scoring errors, reduces administration tasks, and provides easier access to progressmonitoring results and more clear connection between assessments and instructional decision making (Hupert \& Heinze, 2006). In a usability study of teachers' use of DDtrac (Gregg, 2009), teachers reported that "the largest problem ... was a perceived need to collect data on paper and then transfer the data to DDtrac" (p. 462). The developers have since developed DDtrac Mobile to support data collection on web-enabled smartphones. Our own usability testing of the IGDI data system showed that, on average, entering a single assessment into the data system took about 2.5 times longer (about 4 minutes) than the second-longest task (entering a new child into the data system) and 5-10 times longer than most other tasks (Buzhardt et al., 2007). In the case of a child who is receiving monthly progress-monitoring assessments (i.e., is at least $1 \mathrm{SD}$ below age-based norms) over the course of 2 years, this adds up to over 1.5 hours of data entry for a single child. An IGDI mobile "app" that allows assessors to score and submit results in real time with a smartphone rather than scoring assessments on paper and entering them into the data system later would eliminate this step. Additionally, MOD recommendations could be immediately generated by the app for immediate review and discussion with caregivers during the home visit. Figure 4 shows what the MOD's data-based decision-making process might look like if utilized by a mobile app on an Androidbased smartphone.

Despite the promising advantages to using mobile devices for progress monitoring and decision making, there are potential drawbacks to be considered as well. Perhaps the most significant consideration of mobile progress monitoring is ensuring the security of child assessment data. Although data security is a concern regardless of the device used (mobile or desktop), mobile devices, because of their small size and mobility, are more susceptible to being lost or stolen. Also, the use of mobile devices in the field requires transmission of data over cellular networks or potentially unknown wireless networks. Without staff training on appropriate use of mobile devices and software protection installed on the devices, child and family records may be vulnerable. Another consideration is the potential for home visitors to be diverted from engagement with the family and child because of their use of the mobile device during home visits. Like many modern mobile apps, CDSS apps designed for use during home visits could use the phone's built-in GPS system to limit the phone's functionality (e.g., native functionality such as text messaging and web browsing, as well as the CDSSs functionality) when it is beyond predefined boundaries such as the service agency's office or the user's home.

\section{CONCLUSIONS}

In this era of increased accountability, budgets cuts, and demands for evidence-based practices, there is a growing need for tools that allow early childhood practitioners to use progress-monitoring data more effectively and efficiently. On the surface, using computer-based technology to support progress monitoring and data-based intervention decision making seems to be such a natural fit that it precludes the need for research to confirm its value. And, in some ways, it is. There are obvious cost savings and reductions in administrative and data-management efforts to be realized when child assessment data are centrally located, managed, and automatically analyzed and graphed. However, as nearly a century of research in educational technology has demonstrated, 


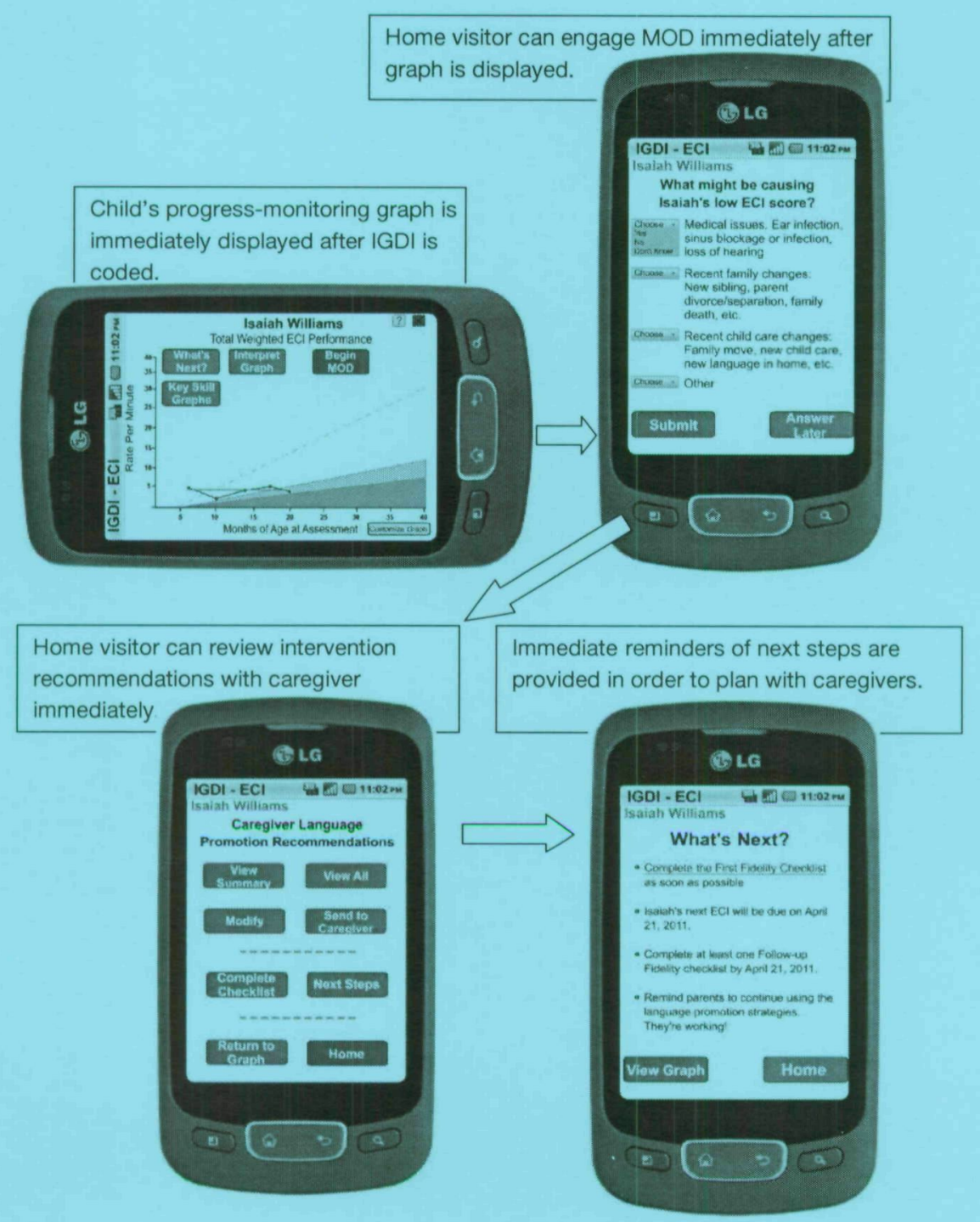

FIGURE 4.

Mock-up illustrations of how mobile devices could be used to facilitate data-based decision making during home visits

the effectiveness of a computer-based program is dependent on how it is designed and implemented, not the technology or medium of delivery (Clark, 1994; Kulik, Kulik, \& Schwalb, 1986). In other words, developing an application that uses the latest cutting-edge technology does not guarantee success without careful consideration of the context in which it is used and the purpose for which it is intended.

Several web-based CDSSs are available for use by $\mathrm{K}-12$ educators to monitor progress and inform instructional planning within a data-based decision-making model. Fewer are available for early childhood. We know from the medical literature that the most effective CDSSs are those that automatically prompt practitioners through the decision-making process, that are easy to integrate into existing practice, that can interface with existing healthcare data systems, and that are usable within a variety of contexts for users with a range of technology experience. Although we can learn from the medical literature, the promise of CDSSs to make data-based decision making more efficient, accelerate the onset of early intervention, and improve outcomes 
for young children with or at risk of disabilities will not be realized without rigorous research of these tools with early childhood practitioners and the children and families they serve.

\section{REFERENCES}

Administration on Children Youth and Families, and Head Start Bureau. (2002). The Head Start path to positive child outcomes: The Head Start Child Outcomes Framework. Washington, DC: U.S. Department of Health and Human Services.

Ahmadian, L., van Engen-Verheul, M., Bakhshi-Raiez, F., Peek, N., Cornet, R., de Keizer, N. (2011). The role of standardized data and terminological systems in computerized clinical decision support systems: Literature review and survey. International Journal of Medical Informatics, 80, 81-93.

AIMSweb (2011). Five-year, expanded contract for Pearson's AIMSweb ${ }^{\circledR}$ system after experiencing more than a decade of academic gains. Retrieved from http://bit.ly/peW1du

Astuto, J., \& Allen, L. (2009). Home visitation and young children: An approach worth investing in? SRCD Social Policy Report, 23(4), $1-22$.

Baggett, K. M., \& Carta, J. J. (2006). Using assessment to guide socialemotional intervention for very young children: An individual growth and development indicator (IGDI) of parent-child interaction. Young Exceptional Children Monograph Series, 8, 67-76.

Baggett, K., Davis, B., Feil, E., Sheeber, B., \& Landry, S. (2010). Webbased tools to support the use of data-based early intervention decision making. Topics in Early Childhood Special Education, 29(4), 201-214.

Ball, C. R., \& Trammell, B. A. (2011). Response-to-intervention in high-risk preschools: Critical issues for implementation. Psychology in the Schools, 48, 502-512.

Barnett, D. A., VanDerHeyden, A. M., \& Witt, J. C. (2007). Achieving science-based practice through response to intervention: What it might look like in preschools. Journal of Educational and Psychological Consultation, 17, 31-54.

Barnum, C. (2002). Usability Testing and Research. New York: Longman.

Bigelow, K. M., Carta, J. J., \& Lefever, J. B. (2008). Using cellular phone technology to enhance a parenting intervention for families at risk for neglect. Child Maltreatment, 13(4), 362-367.

Bricker, D., \& Pretti-Frontczak, K. (1997). A study of psychometric properties of the Assessment, Evaluation, and Programming Test for Three to Six Years. Unpublished report, Center on Human Development, Early Intervention Program, University of Oregon, Eugene.

Bricker, D., Yovanoff, P., Capt, B., \& Allen, D. (2003). Use of a curriculum-based measure to corroborate eligibility decisions. Journal of Early Intervention, 26(1), 20-30.

Burns, M. K., Appleton, J. J., \& Stehouwer, J. D. (2005). Meta-analysis of response to intervention research: Examining field-based and research-implemented models. Journal of Psychoeducational Assessment, 23, 381-394.

Burns, M., Scholin, S., Kosciolek, S., \& Livingston, J. (2010). Reliability of decision-making frameworks for response to intervention for reading. Journal of Psychoeducational Assessment, 28, 102-114.

Buzhardt, J., Abbott, M., Greenwood, C., \& Tapia, Y. (2005). Usability testing of the ClassWide Peer Tutoring Learning Management System. Journal of Special Education Technology, 20(1), 19-29.
Buzhardt, J., Greenwood, C. R., Walker, D., Anderson, R., Howard, W. J., \& Carta, J. J. (2011). Effects of web-based support on Early Head Start home visitors' use of evidence-based intervention decision making and growth in children's expressive communication. NHSA Dialog: A Research-to-Practice Journal for the Early Childhood Field, 13(3), 121-146.

Buzhardt, J., Greenwood, C., Walker, D., Carta, J., Terry, B., Abbott, M. (2007, November). Online progress monitoring and data-based decision making for infants and toddlers. Presentation at the 2007 National Center for Technology Innovation annual conference, Washington, DC.

Buzhardt, J., Greenwood, C., Walker, D., Carta, J., Terry, B., Garrett, M. (2010). A web-based tool to support data-based early intervention decision making. Topics in Early Childhood Special Education, 29(4), 201-213.

Buzhardt, J, \& Heitzman-Powell, L. (2005a). Stop blaming the teachers: The role of usability testing in bridging the gap between educators and technology. Electronic Journal for the Integration of Technology in Education, 4, 1-19.

Buzhardt, J., \& Heitzman-Powell, L. (2005b). Training behavioral aides with a combination of online and face-to-face procedures. Teaching Exceptional Children, 37(5), 20-26.

Buzhardt, J., \& Walker, D. (2010). Web-based support for decision making using IGDIs. In J. Carta, C. Greenwood, D. Walker, \& J. Buzhardt, (Eds.), Using IGDIs: Monitoring Progress and Improving Intervention for Infants and Young Children, (pp. 127-142). Baltimore: Brookes.

Carnine, D. (1997). Bridging the research-to-practice gap. Exceptional Children, 63(4), 513-521.

Carta, J. J., Greenwood, C. R., Walker, D., \& Buzhardt, J. (2010). Using IGDIs: Monitoring progress and improving intervention for infants and young children. Baltimore: Brookes.

Chard, D. J., Harn, B., Sugai, G., Horner, R., Simmons, D., \& Kame'enui, E. (2008). Core features of multi-tier systems of reading and behavioral support (pp. 31-60). In C. R. Greenwood, T. Kratochwill, \& M. Clement (Eds.), School-wide prevention models: Lessons learned in elementary schools. New York: Guilford.

Clark, R. E. (1994). Media will never influence learning. Educational Technology, Research \& Development, 42(2), 21-29.

Classen, D. (1998). Clinical decision support systems to improve clinical practice and quality of care. The Journal of the American Medical Association, 280(15), 1360-1361.

Codding, R. S., Skowron, J., \& Pace, G. M. (2005). Back to basies: Training teachers to interpret curriculum-based measurement data and create observable and measurable objectives. Behavioral Interventions, 20, 165-176.

Coleman, M., Buysse, V., \& Neitzel, J. (2006). Recognition and response: An early intervening system for young children at-risk for learning disabilities. Chapel Hill, NC: Frank Porter Graham.

Crowe, L. (2002). The language intervention toolkit. Topeka: Kansas Department of Social and Rehabilitative Services.

Dell, A., Newton, D., \& Petroff, J. (2011). Uses of technology in early intervention. In C. Groark, S. Eidelman, S. Maude \& L. Kaczmarek (Eds.), Early childhood intervention: Shaping the future for children with special needs and their families (pp. 117-146). Santa Barbara, CA: Praeger.

Deno, S. L. (1997). Whether thou goest...Perspectives on progress monitoring. In J. W. Lloyd, E. J. Kameenui \& D. Chard (Eds.), Issues in educating students with disabilities (pp. 77-99). Mahwah, NJ: Lawrence Erlbaum Associates. 
Dieker, L., Hynes, M., Hughes, C. E., \& Smith, E. (2008). Implications of mixed reality and simulation technologies on special education and teacher preparation. Focus on Exceptional Children, 40(6), $1-20$.

Division of Early Childhood. (2007). Promoting positive outcomes for children with disabilities: Recommendations for curriculum, assessment, and program evaluation. Missoula, MT: Author. Retrieved from http://www.naeyc.org/files/naeyc/file/positions/PrmtgPositive Outcomes.pdf.

Dunst, C., Bruder, MB, Trivette, C., \& Hamby, D. (2006). Everyday activity settings, natural learning environments, and early intervention practices. Journal of Policy and Practice in Intellectual Disabilities, 3(1), 3-10.

Elmore, R. (1996). Getting to scale with good educational practice. Harvard Educational Review, 66, 1-26.

Fantuzzo, J., \& Yumiko, S. (2005). Validity of the child observation record: An investigation of the relation between COR dimensions and social-emotional and cognitive outcomes in Head Start children. Journal of Psychoeducational Assessment 23(3), 242-260.

Fuchs, D., \& Fuchs, L. (1998). Researchers and teachers working together to adapt instruction for diverse learners. Learning Disabilities Research \& Practice, 13, 126-137.

Fuchs, L. S., \& Fuchs, D. (2003). Can diagnostic assessment information enhance general educators' instructional planning and student achievement? In B. Foorman (Ed.), Prevention and intervention for reading disabilities: Bringing science to scale. New York: York Press.

Fuchs, L. S., Fuchs, D., Hamlett, C. L., \& Stecker, P. M. (1991). Effects of curriculum-based measurement and consultation on teacher planning and student achievement in mathematics. American Educational Research Journal, 28, 617-641.

Fuchs, D., Mock, D., Morgan, P. L., \& Young, C. L. (2003). Responsiveness-to-intervention: Definitions, evidence, and implications for the learning disabilities construct. Learning Disabilities Research \& Practice, 18(3), 157-171.

Garg, A., Adhikari, N., McDonald, H., Rosas-Arellano, M. Devereaux, P., Beyene, J. \& Haynes, R. (2005). Effects of computerized clinical decision support systems on practitioner performance and patient outcomes: A systematic review. Journal of the American Medical Association, 293, 1223-1238.

Gibbs, E. D., \& Teti, D. M. (Eds.). (1990). Interdisciplinary assessment of infants: A guide for early intervention professionals. Baltimore: Brookes.

Gibbs, W. (1997). Taking computers to task. Scientific American, July, 82-89.

Graham, T., Kushniruk, A., Bullard, M., Holroyd, B., Meurer, M., Rowe, B. (2008). How usability of a web-based clinical decision support system has the potential to contribute to adverse medical events. American Medical Informatics Proceedings, 2008, 257-261.

Greenwood, C. R., \& Abbott, M. (2001). The research to practice gap in special education. Teacher Education and Special Education, 24(4), 276-289.

Greenwood, C. R., Bradfield, T., Kaminski, R., Linas, M., Carta, J. J., Nylander, D. (2011). The response to intervention (RTI) approach in early childhood. Focus on Exceptional Children, 43(9), 1-22.

Greenwood, C. R., Carta, J. J., Baggett, K., Buzhardt, J., Walker, D., \& Terry, B. (2008). Best practices in integrating progress monitoring and response-to-intervention concepts into early childhood systems. In A. Thomas, J. Grimes \& J. Gruba (Eds.), Best practices in school psychology $V$ (pp. 535-548). Washington, DC: National Association of School Psychology.
Greenwood, C. R., Luze, G. J., Cline, G., Kuntz, S., \& Leitschuh, C. (2002). Developing a general outcome measure of growth in movement for infants and toddlers. Topics Early Childhood Special Education, 22(3), 143-157.

Greenwood, C., Walker, D., \& Buzhardt, J. (2010). The Early Communication Indicator $(\mathrm{ECI})$ for infants and toddlers: Growth norms from two states. Journal of Early Intervention, 32(5), 310-334.

Greenwood, C. R., Walker, D., Carta, J. J., \& Higgins, S. (2006). Developing a general outcome measure of growth in the cognitive abilities of children 1 to 4 years old: The Early Problem-Solving Indicator. School Psychology Review, 35(4), 535-551.

Greenwood, C. R., Walker, D., Hornback, M., Nelson, C., Hebbeler, K., \& Spiker, D. (2007). Progress developing the Kansas Early Childhood Special Education Accountability System: Initial findings using the ECO Child Outcome Summary Form (COSF). Topics in Early Childhood Special Education, 27(1), 2-18.

Gregg, D. (2009). Developing a collective intelligence application for special education. Decision Support Systems, 47, 455-465.

Gresham, F. M. (2007). Evolution of the response-to-intervention concept: Empirical foundations and recent developments. In S. Jimerson, M. Burns, A. VanDerHeyden (Eds.) Handbook of response-to-intervention: The science and practice of assessment and intervention. New York: Springer Science.

Grisham-Brown, J. L., Hallam, R., \& Brookshire, R. (2006). Using authentic assessment to evidence children's progress towards early learning standards. Early Childhood Education Journal, 34(1), $47-53$.

Hamad, C. D., Serna, R. W., Morrison, L., \& Fleming, R. (2010) Extending the reach of early intervention training for practitioners: A preliminary investigation of an online curriculum for teaching behavioral intervention knowledge in autism. Journal of Early Intervention, 23(3), 1-15.

Hebbeler, K., Barton, L. R., \& Mallik, S. (2008). Assessment and accountability for programs serving young children with disabilities. Exceptionality, 16(1), 2-18.

Heitzman-Powell, L., \& Buzhardt, J. (May, 2011). Effective ABA Training for parents of children with autism in geographically remote areas. Presentation for the National Association of Rehabilitation Research Training Centers annual conference, Bethesda, MD.

High/Scope Educational Research Foundation (2005). Appendix B: Infant-toddler COR development and validation. Retrieved from http://www.onlinecor.net/Content.asp?Contentld=2

Hojnoski, R. L., Caskie, G. I. L., Gischlar, K., Key, J. M., \& Barry, A. (2009). Data display: Preference, acceptability, and accuracy among urban Head Start teachers. Journal of Early Intervention, $32(1), 38-53$.

Horton, C., \& Bowman, B. (2002). Child assessment at the preprimary level: Expert opinion and state trends. Chicago: Erikson Institute.

Hunt, D., Haynes, R., Hanna, S., \& Smith, K. (1998). Effects of computer-based clinical decision support systems on physician performance and patient outcomes: a systematic review. Journal of the American Medical Association, 280, 1339-1346.

Hupert, N. \& Heinze, J. (2006). Results in the palms of their hands: Handheld computers for data-driven decision making in the classroom. In M. Van't Hooft and K. Swan (Eds.) Ubiquitous computing in education: Invisible technology, visible impact. Florence, KY: Routledge.

Ingram, M. (2010). Mary Meeker: Mobile internet will soon overtake fixed internet. Retrieved from http://gigaom.com/2010/04/12/ mary-meeker-mobile-internet-will-soon-overtake-fixed-internet/ 
Institute of Education Sciences (2011). Request for applications: Special education research grants (CFDA Number: 84.324.A). Washington, DC: U.S. Department of Education.

Johnson, E., Mellard, D., Fuchs, D., \& McKnight, M. (2006). Responsiveness to intervention (RTI): How to do it. Lawrence, KS: National Research Center on Learning Disabilities.

Kawamoto, K. \& Lobach D. (2003) Clinical decision support provided within physician order entry systems: a systematic review of features effective for changing clinician behavior. Annual Symposium Proceedings for the American Medical Informatics Association, 361-365.

Kelso, G., Fiechtl, B., Olsen, S., Rule, S. (2009). The feasibility of virtual home visits to provide early intervention: A pilot study. Infants and Young Children, 22(4), 332-340.

King-Sears, M. (2001). Institutionalizing peer-mediated instruction and interventions in schools. Remedial and Special Education, 2(22), 89-101.

Kinzie, M. B., Whitaker, S. D., Neesen, K., Kelley, M., Matera, M., \& Pianta, R. C. (2006). Innovative web-based professional development for teachers of at-risk preschool children. Educational Technology \& Society, 9(4), $194-204$.

Kulik. C.-L. C., Kulik, J., \& Schwalb, B. (1986). The effectiveness of computer-based adult education: A meta-analysis. Journal of Educational Computing Research, 2, 235-252.

Kushniruk, A., Triola, M., Stein, B., Borycki, E., \& Kannry, J. (2004). The relationship of usability to medical error: an evaluation of errors associated with usability problems in the use of a handheld application for prescribing medications Medinfo, 2004, 1073-1076.

Lehmann, C (2011, July). Change now: The urgency of school reform. Keynote presentation at the 2011 Annual Conference for the International Society for Education Technology, Philadelphia, PA.

Linas, M. W., Carta, J. J., \& Greenwood, C. R. (2009, June). Taking a snapshot of early childhood response to intervention across the United States. Paper presented at the Fourth Annual IES research conference, Washington, DC.

Linas, M. W., Carta, J. J., \& Greenwood, C. R. (2010, June). Taking a snapshot of early childhood response to intervention across the United States: 2009 and 2010. Washington, DC: Head Start research conference.

Love, J. (2005). The effectiveness of Early Head Start for 3-year-old children and families: Lessons for policy and programs. Developmental Psychology, 41(6), 885-901.

Ludlow, B. L., \& Duff, M. C. (2002). Live broadcasting online: Interactive training for rural special educators. Rural Special Education Quarterly, 21(4), 26-30.

Luze, G. J., Linebarger, D. L., Greenwood, C. R., Carta, J. J., Walker, D., Leitschuh, C., \& Atwater, J. B. (2001). Developing a general outcome measure of growth in expressive communication of infants and toddlers. School Psychology Review, 30(3), 383-406.

Madigan, I. (n.d.). Defining, assessing and supporting quality in early childhood care and education: The High/Scope Ireland model. Retrieved from http://www.cecde.ie/english/pdf/Questions\%20of $\% 20$ Quality/Madigan.pdf

Margolis, C., Warshawsky, S., Goldman, L., Dagan, O., Wirtschafter, D., \& Pliskin, J. (1992). Computerized algorithms and pediatricians' management of common problems in a community clinic. Academic Medicine, 67(4), 282-284.

McCullough, A. (2001). Viability and effectiveness of teletherapy for pre-school children with special needs. International Journal of Language \& Communication Disorders, 36, 321-326.
McNichol, E., Oliff, P., \& Johnson, N. (2011). States continue to feel recession's impact. Center on Budget and Policy Priorities. Retrieved from http://www.cbpp.org/cms/?fa=view\&id=711

Moxey, A., Robertson, J., Newby, D., Hains, I., Williamson, M., \& Pearson, S.-A. (2010). Computerized clinical decision support for prescribing: Provision does not guarantee uptake. Journal of the American Medical Informatics Association, 17, 25-33.

National Association of State Directors of Special Education. (2005). Response to intervention: Policy considerations and implementation. Alexandria, VA: Author.

National Early Childhood Technical Assistance Center. (2008). Timeline for reporting early childhood outcomes. Retrieved from http:// www.fpg.unc.edu/ eco/assets/pdfs/Timeline_for_Reporting_Early _Childhood_Outcomes_Aug_2008.pdf

Nielsen, J. (1993). Usability engineering. San Diego, CA: Academic Press.

Neisworth, J. T., \& Bagnato, S. J. (2004). The mismeasure of young children: The authentic assessment alternative. Infants \& Young Children, 17(3), 198-212.

Nilasena, D., \& Lincoln, M. (1995). A computer-generated reminder system improves physician compliance with diabetes preventive care guidelines. Proceedings of the Annual Symposium of Computer Applied Medical Care, 640-645.

Notari, A., \& Bricker, D. (1990). The utility of a curriculum-based assessment instrument in the development of individualized education plans for infants and young children. Journal of Early Intervention, $14(2), 117-132$.

Odom, S., \& Wolery, M. (2003). A unified theory of practice in early intervention/early childhood special education. The Journal of Special Education, 37(3), 164-173.

Office of Special Education Programs (OSEP). (2010). Application for new grants under the Individuals with Disabilities Act (IDEA): Steppingstones of technology innovation for children with disabilities (CFDA Number: 84.327A). Washington, DC: U.S. Department of Education.

Parrish, D. M., \& Phillips, G. (2003). Developing an early childhood outcomes system for OSEP: Key considerations. Washington, DC: American Institutes for Research.

Pew Internet Project (2010). Home broadband adoption, 2000-2010. Retrieved from http://pewinternet.org/Static-Pages/Trend-Data/ Home-Broadband-Adoption.aspx

Pew Internet Project (2011). Internet adoption, 1995-2010. Retrieved from http://pewinternet.org/Static-Pages/Trend-Data/Internet-Ado ption.aspx

Powell, D. R., Diamond, K. E., \& Koehler, M. J. (2010). Use of a casebased hypermedia resource in an early literacy coaching intervention with pre-kindergarten teachers. Topics in Early Childhood Special Education, 29(4), 239-249.

Raikes, H., Green, B. L., Atwater, J., Kisker, E., Constantine, J., \& Chazan-Cohen, R. (2006). Involvement in Early Head Start home visiting services: Demographic predictors and relations to child and parent outcomes. Early Childhood Research Quarterly, 2l(1), 2-24.

Roehrig, A. D., Duggar, S. W., Moats, L., Glover, M., \& Mincey, B. (2008). When teachers work to use progress monitoring data to inform literacy instruction: Identifying potential supports and challenges. Remedial and Special Education, 29, 364-382.

Rous, B., McCormick, K., Gooden, C., and Townley, K. F. (2007). Kentucky's early childhood continuous assessment and accountability system: Local decisions and state supports. Topics in Early Childhood Special Education, 27(1), 19-33. 
Rubin, J. \& Chisnell, D. (2008). Handbook of usability testing: How to plan, design, and conduct effective tests (2nd Ed). Boston: Wiley.

Sandall, S. R., Schwartz, I. S., \& LaCroix, B. (2004). Interventionists' perspectives about data collection in integrated early childhood classrooms. Journal of Early Intervention, 26, 161-174.

Shonkoff, J., \& Phillips (2000). From neurons to neighborhoods: The science of early childhood development. Washington, DC: National Academy Press.

Smith, A. (2010a). Home broadband 2010: Summary of findings. Pew internet and American life project. Retrieved from http:// www.pewinternet.org/Reports/2010/Home-Broadband-2010/Sum mary-of-Findings.aspx

Smith, A. (2010b). Mobile access 2010: Internet use and data applications using mobile phones. Pew internet and American life project. Retrieved from http://www.pewinternet.org/Reports/2010/ Mobile-Access-2010/Part-2.aspx

Snow, C. E., \& Van Hemel, S. B., (Eds.) (2008). Early childhood assessment: Why, what, and how? A report of the National Research Council of the National Academies. Washington, DC: National Academies Press.

Stedron, J. (2009). A look at Maryland's Early Childhood Data System. National conference of state legislatures. Retrieved from http:// www.dataqualitycampaign.org/resources/details/1049

Steinhauer, J. (2011, March 10). Cuts to Head Start show challenge of fiscal restraint. The New York Times. Retrieved from http:// www.nytimes.com/2011/03/11/us/politics/11 headstart.html

Tilly, W. D. (2008). The evolution of school psychology to a sciencebased practice: Problem solving and the three-tiered model. In A. Thomas \& J. Grimes (Eds.), Best practices in school psychology V (Vol. 1, pp. 17-36). Bethesda, MD: National Association of School Psychologists.

U.S. Department of Education. (2002). Questions and answers on No Child Left Behind. Retrieved from http:/Awww.ed.gov/nclb/methods/whatworks/doing.html

U.S. Department of Education. (2009). Race to the Top program: Executive summary. Retrieved from www.whitehouse.gov/the-pressoffice/fact-sheet-race-top

U.S. Department of Education. (2010). Educational technology in U.S. public schools: Fall 2008. National Center for Education Statistics. (NCES 2010-034).

U.S. Department of Education. (2011). Obama administration announces proposed requirements for Race to the Top-early learning grants. Retrieved from http://1.usa.gov/jTA3WV

Usability Professionals' Association (2011). Resources: Usability in the real world. Bloomingdale, IL: Usability Professionals Association. Retrieved from http://www.upassoc.org/usability_resources/ usability_in_the_real_world/roi_of_usability.html
VanDerHeyden, A. M. (2005). Intervention-driven assessment practices in early childhood/early intervention: Measuring what is possible instead of what is present. Journal of Early Intervention, 28, 28-33.

VanDerHeyden, A. M., \& Burns, M. (2010). The essentials of response to intervention. Boston: Wiley \& Sons.

VanDerHeyden, A. M., \& Snyder, P. (2006). Integrating frameworks from early childhood intervention and school psychology to accelerate growth for all young children. School Psychology Review, $35(4), 519-534$.

Vismara, L., Young, G., Stahmer, A., Griffith, E., \& Rogers, S. (2009). Dissemination of evidence-based practice: Can we train therapists from a distance? Journal of Autism and Developmental Disorders, 39(12), 1636-1651.

Walker, D., Bigelow, K., Harjusola-Webb, S., Small, C., \& Kirk, S. (2004). Strategies for promoting communication and language of infants and toddlers manual. Kansas City, KS: Juniper Gardens Children's Project.

Walker, D., Carta, J. J., Greenwood, C. R., \& Buzhardt, J. (2008). The use of Individual Growth and Developmental Indicators for progress monitoring and intervention decision making in early education. Exceptionality, 16(1), 33-47.

Walker, H., \& Shinn, M. (2010). Systematic, evidence-based approaches for promoting positive student outcomes within a multitier framework: Moving from efficacy to effectiveness. In M. R. Shin \& H. M. Walker (Eds.), Interventions for achievement and behavior problems in a three-tier model including RTI (pp. 1-26). Washington, DC: National Association of School Psychologists.

Wartella, E., Schomburg, R. L., Lauricella, A. R., Robb, M., \& Flyenn, R. (2010). Technology in the lives of teachers and classrooms: Survey of classroom teachers and family child care providers. Latrobe, PA: Fred Rogers Center.

Weiss, H., Caspe, M., Lopez, E., (2006). Family involvement in early childhood education. Cambridge, MA: Harvard Family Research Project. Retrieved from http://www.gse.harvard.edu/hfrp/projects /fine/resources/research/earlychildhood.html

Weikart, D. (2004). How High/Scope grew: A memoir. Ypsilanti, MI: High/Scope Press.

Wireless Generation (2008). Wireless Generation customer overview. Retrieved from http://www.wgen.net/customer-success/success. html 